\title{
Analysis of the Spatial Patterns of Particulate Pollution in the Persistent Haze in Northeast China: A Case Study in Harbin City
}

\author{
Lei Wang*(***), Jiarong Deng****, Lijin Yang*****, Yunlong Yao**† and Dawei Xu*(***) \\ *College of Landscape Architecture, Northeast Forestry University, Harbin 150040, China \\ **College of Wildlife and Protected Area, Northeast Forestry University, Harbin 150040, China \\ ***Key Lab for Garden Plant Germplasm Development \& Landscape Eco-restoration in Cold Regions of Heilongjiang \\ Province, Harbin 150040, China \\ ****College of Architectural Engineering, Heilongjiang University of Science and Technology, Harbin 130012, China \\ *****College of Mining Engineering, Heilongjiang University of Science and Technology, Harbin 130012, China \\ †Correspondence author: Yunlong Yao; yl.yao@163.com
}

Nat. Env. \& Poll. Tech.

Website: www.neptjournal.com

Received: 16-07-2019

Accepted: 05-10-2019

Key Words:

Spatial Pattern;

Particulate pollution;

Persistent haze;

HYSPLIT-4;

Straw burning

\begin{abstract}
With the help of $\mathrm{PM}_{25}, \mathrm{PM}_{10}$, and the Air Quality Index (AQI) and other air quality data, the posterior trajectory model of the Hybrid Single Particle Lagrangian Integrated Trajectory (HYSPLIT-4) model, having researched fire points of the straw in Harbin City, spatial pattern characteristics and genesis of the persistent haze in Harbin City from $20^{\text {th }}$ October 2016 to $11^{\text {th }}$ November 2016 were analysed. During the study period, the highest value of $\mathrm{PM}_{2.5}$ reached $1880 \mu \mathrm{g} / \mathrm{m}^{3}$, the $\mathrm{PM}_{10}$ reached $1411 \mu \mathrm{g} / \mathrm{m}^{3}$, the daily average concentration was high, and the AQI concentration reached a maximum value on $28^{\text {th }}$ October and $4^{\text {th }}$ November, and the persistent haze phenomenon was the most significant. Besides, the study found that the haze incident and a large quantity of pollutants due to the concentration of burning straw around Harbin had a strong connection. The burning of particulate matter had a significant impact on the region's pollution level. The results of this study contribute to the control of particulate pollution in winter cities of developing countries.
\end{abstract}

\section{INTRODUCTION}

With the rapid industrialization and urbanization in developing countries, air pollution became an increasingly problematic issue in daily life (Seinfeld 2004). Serious environmental problems such as air quality, human health, regional climates, and global climates are influenced by particulate pollution (Wang et al.2014, Cao 2012). Haze in the country has become a multi-regional environmental disaster that cannot be ignored (Li et al. 2017, Fang et al. 2016, Liu et al. 2015, Liang et al. 2015). Harbin City has witnessed severe and persistent hazy weather from $20^{\text {th }}$ October to $11^{\text {th }}$ November, during this time, the heavy air pollution and air quality problems caused the visibility of the atmosphere to decrease, and had significant socio-economic impacts, especially on human health. Analysing the changing features and causes of haze weather in the Harbin area is of great significance for accurately observing and forecasting hazy weather, and reducing disaster loss, and ensuring traffic safety and environmental quality (Ou et al. 2015, Li et al. 2017).

Air quality problems are becoming increasingly prominent in many major cities around the world and reduced visibility in the cities has become a prominent phenomenon. Huang et al. (2014) found that fossil fuel combustion and biomass burning is likely to be important for controlling China's $\mathrm{PM}_{2.5}$ levels and for reducing the environmental, economic, and health impacts resulting from particulate pollution. Appel et al. (1985) analysed the $\mathrm{PM}_{2.5}, \mathrm{PM}_{10}$, and $\mathrm{NO}_{2}$ concentration changes to explain the phenomenon of reduced urban visibility. Marcazzan et al. (2001) studied the concentrations of $\mathrm{PM}_{2.5}$ and $\mathrm{PM}_{10}$ in different seasons in Milan and found that $\mathrm{PM}_{2.5}$ concentrations were higher in winter. Kassomenos et al. (2014), Shen et al. (2016), Fang et al. (2017) found that during fog and haze, changes in the concentration of each pollutant trend is similar and that the degree of change of $\mathrm{NO}_{2}, \mathrm{CO}, \mathrm{PM}_{2.5}$, and $\mathrm{PM}_{10}$ were similar. Seinfeld et al. (2016) studied the impact of particulate matter on human beings in an in-depth study by focusing on the relationship between atmospheric aerosol and air pollution. Gautam (2014) used remote sensing image data to study heavy haze phenomena in a given area and studied the corresponding early warning system to reduce the impact of haze on society. Many studies exist on the characteristics and causes of haze in China, mainly focusing on the causes 
of haze, the weather situation, haze control, haze detection, haze forecast, and so on (Wu 2008, Wu et al. 2008, 2010, Yue et al. 2013). Wu et al. (2016) found that the main factor affecting smog in monitoring points in 74 countries in China was industrial and that the use of motor vehicles and domestic gas was also becoming influential factors, and $\mathrm{Pu}$ (2017) analysed the trend of $\mathrm{PM}_{2.5}$ in different regions of China from an economic development perspective. However, due to the different situations in different countries, there are differences in the time and causes of haze (Fan 2010, Zhang et al. 2017, Han et al. 2016).

Taking Harbin City as an example, this paper analyses the characteristics and causes of haze pollution from $20^{\text {th }}$ October 2016 to $11^{\text {th }}$ November 2016. This paper analyses the air quality status during the pollution period with air quality data and traces the movement of pollutants at different heights through the backward trajectory mode to trace the source of the pollutants. Furthermore, this paper also looks into the distribution of straw fire points in Harbin and discusses the main causes of haze pollution to provide a basis for controlling the impact of haze in Harbin City.

\section{MATERIALS AND METHODS}

\section{Data Collection and Sample}

Based on the data of air quality, Lagrangian hybrid single particle orbit model, and the distribution of the straw fire points, the spatial pattern and genesis of haze were studied in Harbin City.

1) The Air Quality Index (AQI) data and Particulate Matter $(\mathrm{PM})$ are derived from environmental cloud work platforms and mainly analyse the air quality status during the pollution period.
2) The trajectories of pollutants are calculated using the Hybrid Single Particle Lagrangian Integrated Trajectory Model (HYSPLIT) jointly released by the National Oceanic and Atmospheric Administration (NOAA) and the Australian Bureau of Meteorology. The backward trajectory model is used to trace the source and trend of air masses during the pollution period because it can handle the meteorological transmission, diffusion, and settlement at different heights and there are various meteorological input fields and physical processes. The meteorological data were provided by the National Environmental Forecast Center (NCEP) of the United States from the simultaneous global data assimilation system (GDAS) data (Zhang et al. 2017, Ge et al. 2017).

3) The distribution data of the straw fire points in Harbin in autumn comes from the satellite environmental application centre of the Ministry of Environmental Protection, which is used to analyse the situation of straw burning in the surrounding areas of Harbin.

The downtown area of Harbin $\left(45.64^{\circ} \mathrm{N}-45.86^{\circ} \mathrm{N}\right.$, $\left.126.47^{\circ} \mathrm{E}-126.81^{\circ} \mathrm{E}\right)$ is used as the target of the HYSPLIT model and the GDAS data of $28^{\text {th }}$ October 2016 and $4^{\text {th }}$ November 2016 are analysed retrospectively. The back-push time is set at 72 hours, UTC time is 16:00. The interval time is set to six hours and air mass monitoring at three different altitudes is set at $100 \mathrm{~m}, 500 \mathrm{~m}$, and $1000 \mathrm{~m}$, respectively, to monitor the movement trajectories of pollutants at different heights. This draws the Harbin City HYSPLIT-4 backward trajectory model.

\section{Air Quality Analysis of the Smog Process}

Analysis of air pollution during the status of the pollution process can be reviewed and the changes and characteristics

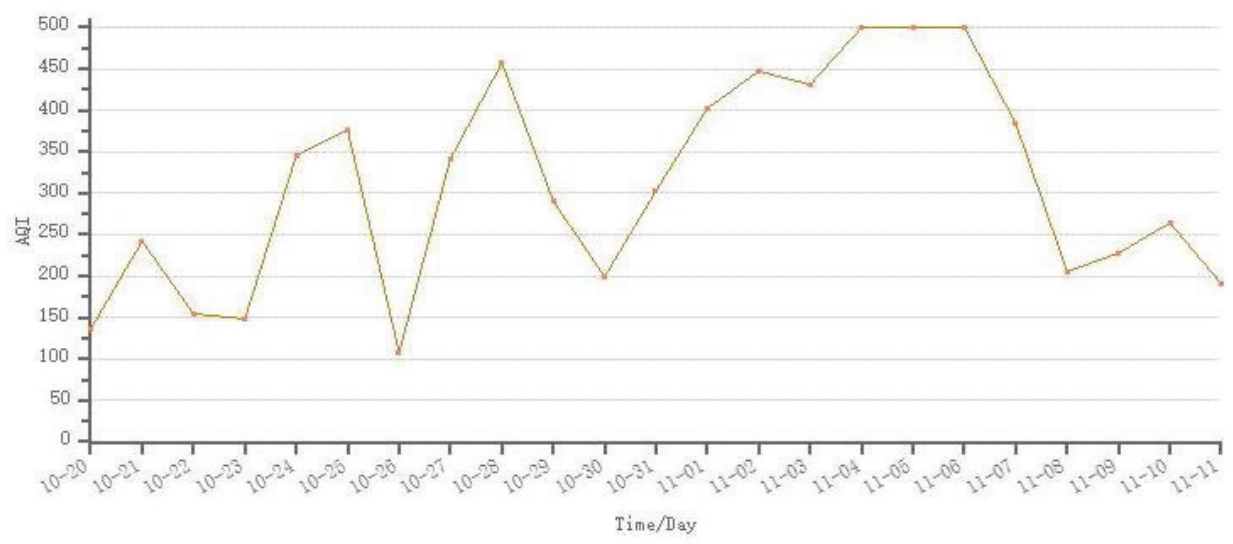

Fig. 1: The Harbin Air Quality index trend map from $20^{\text {th }}$ October to $11^{\text {th }}$ November. 
can be understood. China issued the relevant provisions in the first half of 2012 in which the Air Quality Index (AQI) replaced the original Air Pollution Index (API) and the relevant provisions were implemented on $1^{\text {st }}$ January 2016 (China Meteorological Administration 2010).

From $20^{\text {th }}$ October 2016 to $11^{\text {th }}$ November 2016, the air pollution in Harbin continued for 23 days. The primary pollutants were $\mathrm{PM}_{2.5}$ and $\mathrm{PM}_{10}$. Fig. 1 shows the trend of $\mathrm{AQI}$ during the pollution period. As shown in Fig. 1, the air quality conditions were mildly polluted on $20^{\text {th }}, 22^{\text {th }}, 23^{\text {th }}, 26^{\text {th }}, 30^{\text {th }}$ October, and $11^{\text {th }}$ November. On $21^{\text {th }}$ and $29^{\text {th }}$ October, and on $8^{\text {th }}, 9^{\text {th }}$, and $10^{\text {th }}$ November, the air quality was heavily polluted. On the $24^{\text {th }}, 25^{\text {th }}, 27^{\text {th }}, 28^{\text {th }}$, and $31^{\text {th }}$ of October, and on the $1^{\text {st }}, 2^{\text {nd }}, 3^{\text {rd }}, 4^{\text {th }}, 5^{\text {th }}, 6^{\text {th }}$, and $7^{\text {th }}$ of November, the air quality status showed serious pollution levels. Among these, the AQI on $4^{\text {th }}, 5^{\text {th }}$, and $6^{\text {th }}$ November, exceeded 500. This is the most long-lasting and serious haze pollution in Harbin since $20^{\text {th }}$ October 2016 when the Heilongjiang Provincial Department of Environmental Protection issued a haze red warning. Fig. 2 shows that from $20^{\text {th }}$ October- $11^{\text {th }}$ November, Harbin City's (11 monitoring sites: Lingbei Station, Songbei Shangda Station, Huining Station, Taiping Grand Park Station, Chengde outside the road, Xiangfang Hongqi Street station, He Ping Road station, Daoli Jianguo Road station, Square East Light Station, Hulan Teachers College station, Provincial Academy of Agricultural Station) daily average of $\mathrm{PM}_{2.5}, \mathrm{PM}_{10}, \mathrm{NO}_{2}$, and $\mathrm{SO}_{2}$ levels. The $\mathrm{NO}_{2}$ and $\mathrm{SO}_{2}$ trends are roughly the same, the daily concentrations of $\mathrm{PM}_{2.5}$ and $\mathrm{PM}_{10}$ from $20^{\text {th }}$ October to $11^{\text {th }}$ November were above $100 \mu \mathrm{g} / \mathrm{m}^{3}$; on $4^{\text {th }}$ November, the average daily $\mathrm{PM}_{2.5}$ reached its maximum of $1880 \mu \mathrm{g} / \mathrm{m}^{3}$. On 5th November, $\mathrm{PM}_{10}$ reached its maximum of $1411 \mu \mathrm{g} / \mathrm{m}^{3}$, corresponding to an AQI of 500 and severe air quality conditions. After $6^{\text {th }}$ November, the $\mathrm{PM}_{2.5}$ and $\mathrm{PM}_{10}$ daily average concentrations showed a downward trend.

\section{RESULTS AND DISCUSSION}

\section{Analysis of the Backward Trajectory of Air Mass}

Using the HYSPLIT-4 model, GDAS meteorological data, and UTC time, we analysed two of the most severe smog hazes during the study period, with the AQI value reaching 458 at 3:00 AM on $28^{\text {th }}$ October 2016 and 500 at 4:00 PM on $4^{\text {th }}$ November 2016. Using the model, we calculated the 72-hour backward transfer trajectory, as shown in Figs. 3 and 4 . The red, blue, and green trajectories in the images represent the air mass transport trajectories at the low altitude of $100 \mathrm{~m}$ and the high altitudes of $500 \mathrm{~m}$ and $1000 \mathrm{~m}$ in the air. As can be seen in Fig. 3, the 100-meter low air mass began at 00:00 on $25^{\text {th }}$ October and moved northeastward from Inner Mongolia to the northeast at noon on the $25^{\text {th }}$. It moved southwards along the eastern boundary of Inner Mongolia and entered the provinces of Jilin and Liaoning at noon on the $26^{\text {th }}$ and then the air mass moved north again and finally arrived in Harbin. The 500-meter and 1000-meter air masses showed roughly similar movement trends with the declining phenomenon. The 500-meter air mass at 0:00 on the $25^{\text {th }}$ rose to $1000 \mathrm{~m}$ and then gradually decreased at 0:00 on the $26^{\text {th }}$ down to $100 \mathrm{~m}$. The height of the 1000 -meter air mass at 0:00 on the $25^{\text {th }}$ dropped to about $100 \mathrm{~m}$ and then at 12:00 on the $27^{\text {th }}$, the air mass rose to more than $500 \mathrm{~m}$ and moved from Southern Inner Mongolia to the Liaoning area, and then turned to the north, eventually reaching Harbin. It can be seen that part of the heavy haze on the 28th is due to the descent of the high air mass, transporting high-altitude pollutants to a low altitude and transporting low-level pollutants from other regions to Harbin. In Fig. 4, it can be seen that the 100-meter low-level air mass reaches Harbin from the south from Russia, but in the case of high pressure in Russia, the air mass rises from 0:00 on 1st November, and

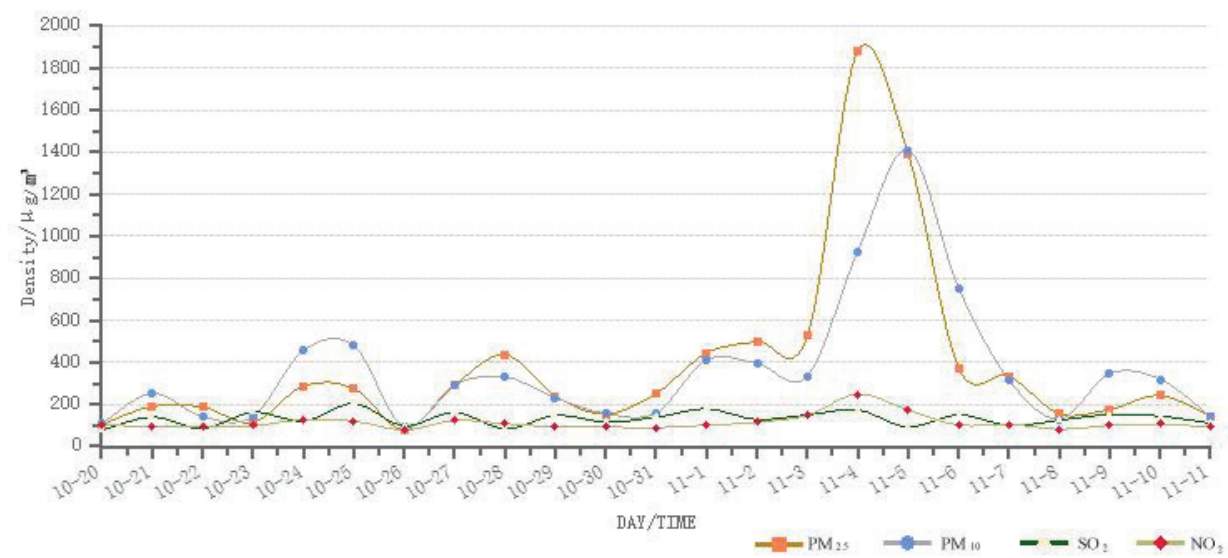

Fig. 2: The daily concentration changes of $\mathrm{PM}_{2.5}, \mathrm{PM}_{10}, \mathrm{NO}_{2}$ and $\mathrm{SO}_{2}$ in Harbin from $20^{\text {th }}$ October to $11^{\text {th }}$ November. 


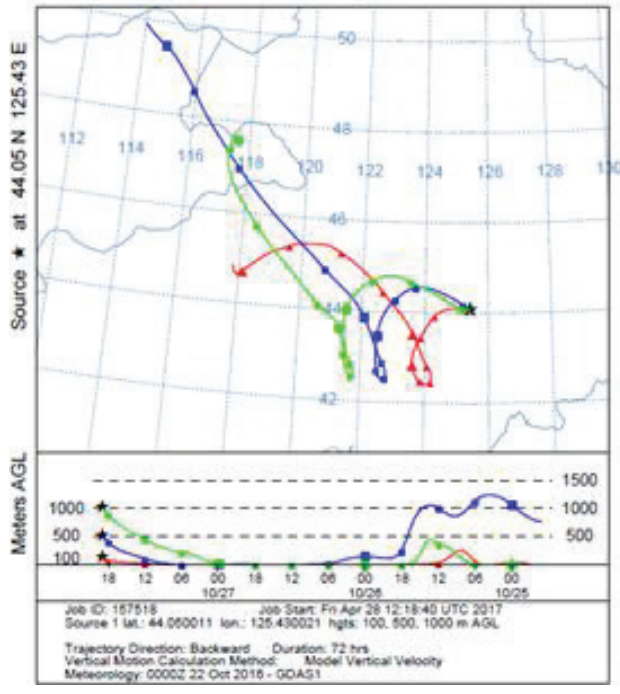

Fig. 3: The 72 hours back trajectory map on $28^{\text {th }}$ October.

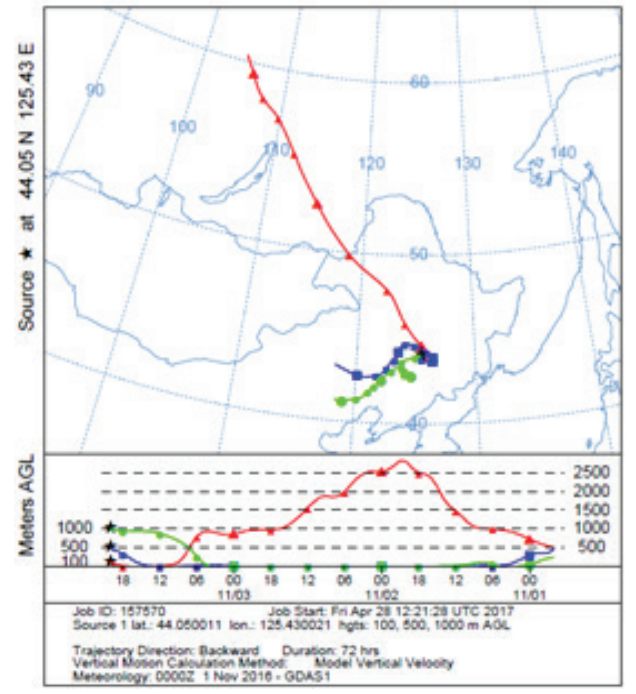

Fig. 4: The 72 hours back trajectory map on $4^{\text {th }}$ November. the air mass continues to rise to a height of about $2500 \mathrm{~m}$ at 20:00 on January 1, then it gradually declines. At 12:00 on the $3^{\text {rd }}$ November, it drops to about $100 \mathrm{~m}$. The 500 -meter and 1000-meter air masses move in roughly the same direction. They move northward from Hebei and Inner Mongolia and are at a height of about $100 \mathrm{~m}$ from $1^{\text {st }}$ November- $3^{\text {rd }}$ November at 6:00. The air mass carrying particulate contaminants did not rise to the original altitude when it reached Harbin. The reason for the haze on the $4^{\text {th }}$ was because the high air mass had been moving at a low altitude and transported the pollutants in other areas to Harbin.

Combining the trajectories of the air masses on $28^{\text {th }}$ October and $4^{\text {th }}$ November, it can be found that the highair masses are all reduced to low-level movement. The air currents transport the pollutants in the northwestern and southwestern parts of the country to Harbin and the airborne pollutants of Harbin to the lower part of the sky, indicating that part of the reason for the haze weather in Harbin was due to the regional pollution.

\section{Monitoring and Analysis of the Straw Incineration Fire Points}

Heilongjiang Province is a major grain-producing province. After harvesting, a large number of straw burning incidents continue to occur. Small particles floating in the air have caused serious air pollution in Harbin after long-term heating and burning a large amount of coal for heating. This article studies the sources and causes of smog pollution in Harbin from 20th October -11th November. As can be seen from Fig. 2, the AQI reached a peak on October 28th and reached a maximum on 4th November (AQI of 500). Table 1 shows the Ministry of Environmental Protection satellite environment application centre test data. Table 2 shows that in October and November, the number of straw burning stoves in Heilongjiang Province were 702 and 715, respectively. Fig. 5 is from $20^{\text {th }}$ to $31^{\text {st }}$ October, showing the distribution area of straw burning fire spots in Heilongjiang Province, which totalled 598, accounting for $85 \%$ of the total in October. Fig. 6 shows Harbin's burned fire point distribution area of Harbin from

Table 1: The environmental satellite monitoring of the fire points of straw burning in October 2016.

\begin{tabular}{|llll|}
\hline Sort & Province & Fire Points & Fire Intensity (A/thousand hectares of arable land area) \\
\hline 1 & Heilongjiang & 702 & 0.0600 \\
2 & Inner Mongolia & 100 & 0.0177 \\
3 & Jilin & 73 & 0.0146 \\
4 & Liaoning & 58 & 0.0179 \\
5 & Shanxi & 54 & 0.0164 \\
6 & Xinjiang & 35 & 0.0155 \\
\hline
\end{tabular}

Note: The data of arable land in each province in this statistical table comes from the China Statistical Yearbook 2014. 
Table 2: The environmental satellite monitoring of the fire points of straw burning in November 2016.

\begin{tabular}{|llll|}
\hline Sort & Province & Fire Points & Fire Intensity (A/thousand hectares of arable land area) \\
\hline 1 & Heilongjiang & 715 & 0.0611 \\
2 & Shanxi & 94 & 0.0286 \\
3 & Inner Mongolia & 40 & 0.0071 \\
4 & Jilin & 39 & 0.0078 \\
5 & Liaoning & 25 & 0.0077 \\
6 & Hebei & 13 & 0.0021 \\
\hline
\end{tabular}

Note: The data of arable land in each province in this statistical table comes from the China Statistical Yearbook 2014.

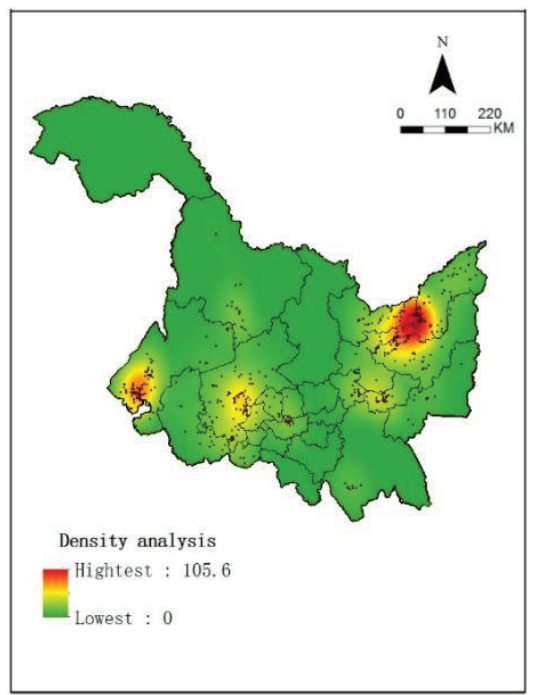

Fig. 5: $20^{\text {th }}-31^{\text {st }}$ October Heilongjiang province straw burning fire points.

$20^{\text {th }}$ to $31^{\text {st }}$ October, with a total of 52 , mainly distributed in Binxian, Bayan County, Acheng District, Tonghe County, Yilan County, Magnolia County, Shuangcheng District, Wuchang City, Daoli District, and Hulan District, of which 18 are from the Yilan County, 12 are from the Bin County and 9 are from the Bayan County. Based on the HYSPLIT-4 model, the source of air pollutants in Harbin was analysed. Combining the distribution of fire density of straw burning in Fig. 5 and Fig. 6, the main cause of smog pollution in Harbin on 28th October is the transportation of extraneous air pollutants. From Fig. 3, it can be seen that the wind on 25 th, 26th, and 27th of October was not conducive to the spread of pollutants. The straw burning from the northwest and southwest areas of Harbin (that is, Shuangcheng, Acheng, Daoli, and Hulan) causes the particles to stay in Harbin, thus exacerbating the extent of ambient air pollution.

Fig. 7 shows the $1^{\text {st }}-11^{\text {th }}$ November Heilongjiang Province Environmental Satellite Monitoring of the straw burning

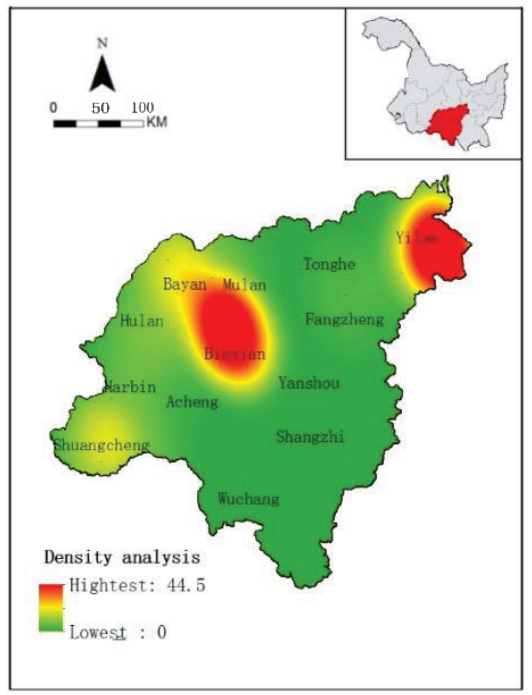

Fig. 6: $20^{\text {th }}-31^{\text {st }}$ October Harbin City straw burning fire points.

fire density distribution area: a total of 715. Fig. 8 shows the $1^{\text {st }}$ to $11^{\text {th }}$ November Harbin Environmental Satellite Monitoring straw burning fire density distribution area: a total of 50, mainly in Bayan County, Bin County, Hulan District, Mulan County, Shuangcheng District, Yilan County, Acheng District, Songbei District, Tonghe County, and Yanshou County. From these, 20 were in the Hulan District, 9 in the Lan County and Bayan County, and 4 in the Binxian County. Compared with October, the incineration points around Harbin urban area increased significantly in November. According to the backward deduction of Fig. 4, the distribution location of straw burning fire spots in Fig. 7 and Fig. 8 resulted in the AQI "explosion table" on November 4 in Harbin mainly due to the transportation of air pollutants from the northwest and southwest directions. As can be seen from Fig. 4, on 1st, 2nd, and 3rd days of November, the 500-meter altitude and the 1000-meter altitudes were windless and due to the 100-meter low air mass movement, the pollutants in 

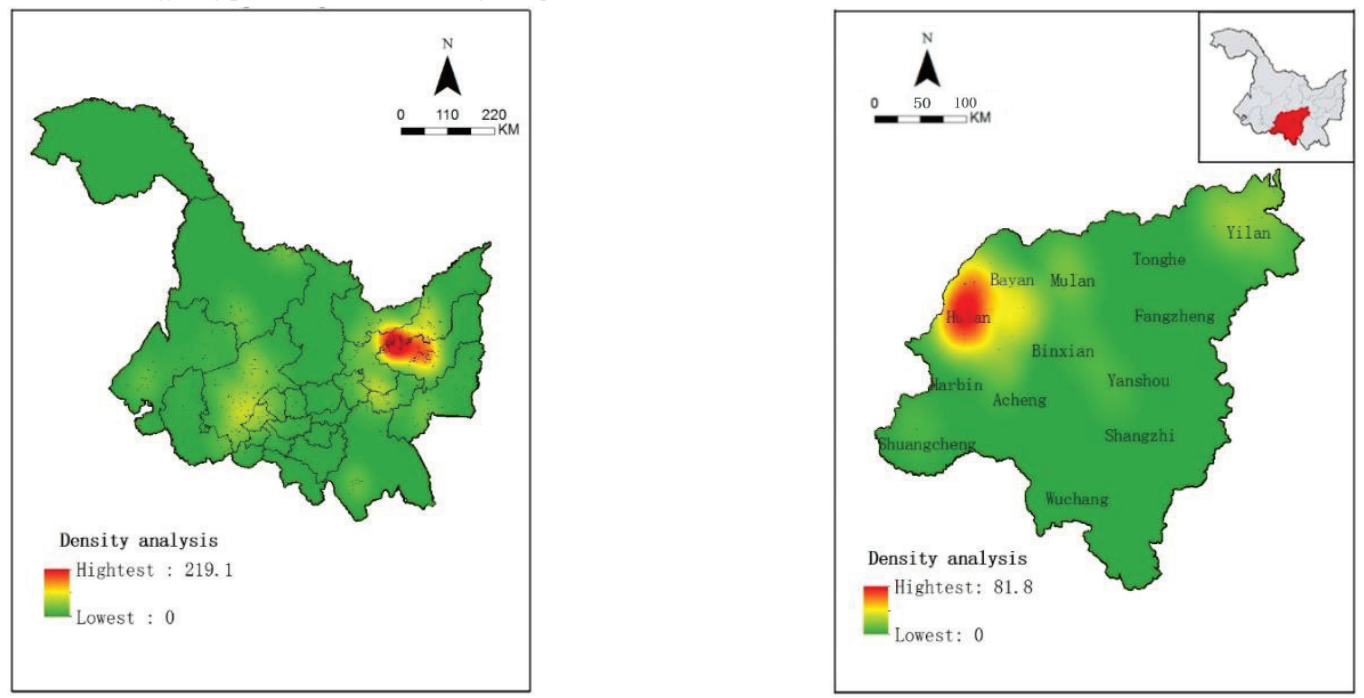

Fig. 7: $1^{\text {st }}-11^{\text {th }}$ November Heilongjiang province straw burning fire points. Fig. $8: 1^{\text {st }}-11^{\text {th }}$ November Harbin City straw burning fire points.

the surrounding area of Harbin were transported to Harbin. Furthermore, a large amount of incinerated particles remain in the Harbin, which further intensified the air pollution.

\section{CONCLUSION}

The Air quality in Harbin has been in a poor state since heating. Based on the air quality data provided by the environmental cloud platform, this paper analyses the air quality status of Harbin from $20^{\text {th }}$ October 2016 to $11^{\text {th }}$ November 2016, period (23 days). In this period, 6 days showed mild pollution and 17 days showed more serious pollution, of which $4^{\text {th }}$ November to $6^{\text {th }}$ November was the most serious, with AQIs exceeding 500. Through the backward trajectory simulation of the HYSPLIT-4 model, we found that the straw burning in the surrounding area of the Heilongjiang Province and Harbin continued for nearly a month, resulting in the main reason of the "explosion table" on the $28^{\text {th }}$ and the $4^{\text {th }}$. The excessive combustion of straw burning in Harbin on the $28^{\text {th }}$ and the high altitude windless conditions are not conducive to the spread of pollutants and cause the straw burning particles to stay in Harbin. During the winter period in Harbin, the temperature is low, and the air mass decreases, thus exacerbating Harbin's urban ambient air quality pollution levels.

This article is a preliminary study on the causes of haze smog, during winter in Harbin. There are still some factors that are not involved and will be further explored in the following research.

\section{ACKNOWLEDGEMENTS}

The authors would like to express gratitude to the research grant support provided by China Postdoctoral Science Foundation (Grant No.2017M621229), Postdoctoral Science Foundation of Heilongjiang Province (Grant No. LBH-Z17001), the National Natural Science Foundation of China for Young Scholars (Grant No. 41101177), Philosophy and Social Science Program in Heilongjiang Province (Grant No. 17GLD173, Grant No. 16GLC04), Scientific Research Foundation for the Returned Overseas Chinese Scholars, Heilongjiang Province, the University Strategic Reserve Personnel Abroad Research project funded by the Heilongjiang Province, Doctoral Fund of Ministry of Education of Heilongjiang Province, University Nursing Program for Young Scholars with Creative Talents in Heilongjiang Province.

\section{REFERENCES}

Appel, B.R., Tokiwa, Y., Hsu, J., Kothny, E.L. and Hahn, E. 1985. Visibility as related to atmospheric aerosol constituents. Atmospheric Environment, 19(9): 1525-1534.

Cao, J. J. 2012. Pollution status and control strategies of $\mathrm{PM}_{2.5}$ in China. Journal of Earth Environment, 3: 1030-1036.

China Meteorological Administration 2010. Observation and Forecast level of Haze in China Meteorological Administration. QX/T113-2010. Beijing: Meteorological Press.

Fan, X.Q. 2010. Study on Haze Weather Characteristics and its Relationship with Atmospheric Environmental Pollution in Xiamen City. Nanjing University of Information Science and Technology.

Fang, C.S., Zhang, Z.D., Jin, M.Y., Zou, P.C. and Wang, J. 2017. Pollution characteristics of $\mathrm{PM}_{2.5}$ aerosol during haze periods in Changchun, China. Aerosol and Air Quality Research, 17(04): 888-895.

Fang, D.Q., Wei, Y.J. and Huang, W. 2016. Characterization and source apportionment of organic carbon during a heavy haze episode in Beijing in October 2014. Research of Environmental Science, 29(1): 12-19.

Gautam, R. 2014. Challenges in early warning of the persistent and widespread winter fog over the Indo-Gangetic plains: A satellite perspective. In: Reducing Disaster: Early Warning Systems for Climate Change. 
Springer, Dordrecht, pp. 51-61.

Ge, Y., Wang, M. X., Bai, X., Yao, J. B. and Zhu, Z. R. 2017. Pollution characteristics and potential sources of $\mathrm{PM}_{2.5}$ in $\mathrm{Su}-\mathrm{Xi}$-Chang region. Acta Scientiae Circumstantiae, 37(03): 803-813.

Han, R., Wang, S.X., Shen, W.H., Wang, J.D., Wu, K., Ren, Z.H. and Feng M.N. 2016. Spatial and temporal variation of haze in China from 1961 to 2012. Journal of Environmental Science, 46: 134-146.

Huang, R.J., Zhang, Y., Bozzetti, C., Ho, K.F., Cao, J.J., Han, Y., Daellenbach, K.R., Slowik, J.G., Platt, S.M., Canonaco, F. and Zotter, P. 2014. High secondary aerosol contribution to particulate pollution during haze events in China. Nature, 514: 218-222.

Kassomenos, P.A., Vardoulakis, S., Chaloulakou, A., Paschalidou, A.K., Grivas, G., Borge, R. and Lumbreras, J. 2014. Study of $\mathrm{PM}_{10}$ and $\mathrm{PM}_{2.5}$ levels in three European cities: Analysis of intra and inter urban variations. Atmospheric Environment, 87: 153-163.

Li, P. W., Haridah, A., Nasrin, A., Azadeh, G and Nik Meriam, N. S. 2017. Control measures and health effects of air pollution: A survey among public transportation commuters in Malaysia. Sustainability, 9(9): 1616

Li, Z., Zhang, H. and Ye, H. 2017. Characteristics of air pollution during typical haze periods and HYSPLIT model analysis of its source in Hangzhou. Acta Scientiae Circumstantiae, 11: 1-16.

Liang, D., Wang, B. and Wang, Y.Q. 2015. Distribution characteristics and sources of $\mathrm{PM}_{2.5}$ and gaseous pollutants in winter in Chongqing. Research of Environmental Science, 28(07): 1039-1046.

Liu, L.W., Li, W.C. and Shang, K.Z. 2015. Analysis of a serious haze process and its impact factors in Jing-jin-Ji region. Journal of Meteorology Environment, 31(1): 35-42.

Marcazzan, G.M., Vaccaro, S. Valli, G. and Vecchi, R. 2001. Characterisation of $\mathrm{PM}_{10}$ and $\mathrm{PM}_{2.5}$ particulate matter in the ambient air of Milan (Italy). Atmospheric Environment, 35(27): 4639-4650.

Ou, N.Y., Wang, W. and Bo, J.F. 2015. An analysis of the causes and characteristics of a rare and persistent haze weather in Harbin.
Heilongjiang Meteorology, 32(2): 1-4.

$\mathrm{Pu}, \mathrm{Z}$. N. 2017. Time-spatial convergence of air pollution and regional economic growth in China. Sustainability, 9(7): 1284.

Seinfeld, J. H. 2004. Air pollution: A half century of progress. American Institute of Chemical Engineers Journals, pp. 1096-1108.

Seinfeld, J. H. and Pandis, S. N. 2016. Atmospheric Chemistry and Physics: From Air Pollution to Climate Change. New York: John Wiley \& Sons.

Shen, L.J., Wang, H.L. and Li, L. 2016. Observation analysis on the characteristics of meteorological elements and pollutants during a continuous fog and haze episode in spring in Jiaxing City. Environmental Science, 37(08): 2871-2880.

Wang, Y., Zhang, R.Y. and Saravanan, R. 2014. Asian pollution climatically modulates mid-latitude cyclones following hierarchical modeling and observational analysis. Nature Communications, 5: 2098.

Wu, D. 2008. Identification and data analysis of haze and fog. Environmental Chemistry, 27(3): 327-330.

Wu, D., Liao, G. L., Deng, X. J., Bi, X. Y., Tan H. P., Li F., Jiang C. L., Xia D. and Fan S. J. 2008. Study on the transport conditions of haze in the Pearl River Delta. Journal of Applied Meteorological Science, 19(1): 1-9.

Wu, D., Wu, X. J., Li, F., Tan, H. P., Chen, Cao, Z. Q., Sun, X., Chen, H. H. and Li, H. Y. 2010. Temporal and spatial changes of haze in Chinese mainland from 1951 to 2005. Journal of Meteorological, 68(5): 680-688.

Wu, J. N., Zhang, P., Yi, H. T. and Zhao, Q. 2016. What causes haze pollution? an empirical study of $\mathrm{PM}_{2.5}$ concentrations in Chinese cities. Administrative Tribune, 8(2): 132.

Yue, Y. F., Liu, D. Y., Zhou, B., Xia, J., Wu, Y. and Hu, Y. H. 2013. Study on haze weather characteristics and influencing factors in Wuxi. Meteorological Monthly, 39(10): 1314-1324.

Zhang, J.Y., Song, S. H., Xu, R. and Wen J. H. 2017. Source analysis of regional air pollution particles based on backward air mass trajectory. Environmental Monitoring in China, (02): 42-46. 